\title{
Hormonal Regulation of Motor Unit Size and Synaptic Strength during Synapse Elimination in the Rat Levator Ani Muscle
}

\author{
Cynthia L. Jordan, ${ }^{1,2}$ Peter A. Pawson, ${ }^{2, a}$ Arthur P. Arnold, ${ }^{1}$ and Alan D. Grinnell ${ }^{2}$ \\ 'Department of Psychology and Laboratory of Neuroendocrinology of the Brain Research Institute and ${ }^{2}$ Jerry Lewis \\ Neuromuscular Research Center, Ahmanson Laboratories, and Department of Physiology, University of California, \\ Los Angeles, California 90024
}

Previous anatomical studies suggest that androgen regulates synapse elimination in the androgen-sensitive levator ani (LA) muscle of the rat. Androgen treatment beginning on postnatal day 7 (P7) prevents some of the normal loss of multiaxonal innervation in this muscle. The present study used physiological techniques to measure the number and size of LA motor units during the synapse elimination period in muscles from normals, and castrates treated with either testosterone propionate or oil. The number of increments in LA twitch tension as nerve stimulation intensity increased, a measure of the number of motor units, was the same at the end (P28) of synapse elimination as near the beginning (P7) of this process. This result indicates that motoneuronal cell death does not contribute to synapse elimination in the LA. Moreover, androgen during this period did not influence the number of LA motor units. In contrast, between P7 and P28, there was a dramatic decline in the size of LA motor units, as indicated by a decrease in the percentage of twitch or tetanus tension of individual motor units relative to the maximal twitch or tetanus tension of the whole muscle. In addition, androgen treatment of castrated males during this period prevented some of the normal decline in the size of LA motor units. Estimates of the number of inputs per LA muscle fiber derived from the number of LA motor units and their average size indicate that androgen maintains polyneuronal innervation in the LA muscle. This finding supports previous anatomical studies suggesting that androgen can prevent synapse elimination in this muscle. The strength of LA synapses was also examined by measuring the tetanus : twitch ratio of individual motor units and by measuring the safety margin of LA synapses. Both measurements indicated that the average strength of LA synapses increases during synapse elimination. Moreover, androgen appeared to spare synapses from elimination without increasing their strength, since androgen-treated muscles generally had larger motor units but the same mean tetanus: twitch ratio and safety margins as untreated LA muscles except at P28, when synapses in androgen-treated LA muscles had appreciably low-

\footnotetext{
Received Apr. 21, 1992; accepted June 11, 1992.

We thank S. Marc Breedlove for useful comments on an earlier version of the manuscript. In addition, we are indebted to Wes Thompson for his generous help during the early stage of this project. This work was supported by NIH Grants HD15021 (A.P.A.) and NS08686 (C.L.J.)

Correspondence should be addressed to Cynthia L. Jordan, Department of Psychology, University of California, Berkeley, CA 94720.

a Present address: University of Ottawa, Faculty of Medicine, Department of Physiology, 451 Smyth Road, Ottawa, Ontario, Canada K1H 8M5.

Copyright (C) 1992 Society for Neuroscience $0270-6474 / 92 / 124447-13 \$ 05.00 / 0$
}

er safety margins than normal. These results suggest that androgen regulates synapse elimination through a mechanism(s) independent of synaptic strength.

Synapse elimination usually occurs during early postnatal development and serves to reduce the initial high number of synaptic connections between neurons and their target cells to the lower number present in adulthood (Purves and Lichtman, 1980; Van Essen, 1982; Jansen and Fladby, 1990). For example, motoneurons initially innervate more muscle fibers, and establish larger motor units, than they do in adulthood (Brown et al., 1976). Consequently, developing mammalian muscle fibcrs arc initially polyneuronally innervated (Redfern, 1970) rather than singly innervated as in adults. During synapse elimination, motoneurons retract a large portion of their axonal arbor (Bixby, 1981; Riley, 1981), thus reducing the size of motor units (Brown et al., 1976; Betz et al., 1979; Fladby, 1987; Balice-Gordon and Thompson, 1988) until the adult pattern of single innervation is established (reviewed in Van Essen, 1982; Thompson, 1986; Betz, 1987; Jansen and Fladby, 1990).

Recent evidence in the androgen-sensitive levator ani (LA) suggests that steroid hormones may be important regulators of synapse elimination (Jordan et al., 1989a,b, 1990). The LA is one of three perineal skeletal muscles present in adult male but not adult female rats (Wainman and Shipounoff, 1941; Cihak et al., 1970). These muscles mediate penile reflexes that are active during male copulatory behavior (Sachs, 1982; Hart and Melese-d'Hospital, 1983; Sachs and Meisel, 1988). Synapse elimination in the LA occurs later than in other rat muscles. At postnatal day 14 (P14), less than $10 \%$ of LA muscle fibers are innervated by single axons (Jordan et al., 1988), suggesting that synapse elimination is just beginning in the LA muscle, rather than ending as in most other rat muscles (Van Essen, 1982; Balice-Gordon and Thompson, 1988; Jordan et al., 1988; Jansen and Fladby, 1990). Between P14 and P28, most LA fibers lose their multiple inputs, although between 60 and $90 \mathrm{~d}$ after birth, there is a secondary phase of synapse elimination in the LA, in which $15 \%$ more fibers lose their multiple inputs (Jordan et al., 1988). Both phases of synapse elimination in the LA appear sensitive to androgen. Castration on P7 accelerates the onset of the early phase by a few days, and the secondary phase occurs a month earlier in castrates (Jordan et al., 1989a,b). These results suggest that synapse elimination in the LA muscle is normally under the control of endogenous androgen, despite the low androgen levels during the first postnatal month (Corpechot et al., 1981). Even more pronounced effects of androgen on synapse elimination were observed when castrated males were given 
doses of exogenous androgen that were designed to mimic the much higher levels normally present in adult males. Androgen treatment of castrated male rats starting after the first postnatal week results in an apparent retention of polyneuronal innervation (Jordan et al., 1989a,b). Between P14 and P28, the percentage of multiply innervated fibers (judged anatomically) normally declines from about $95 \%$ to $30 \%$. However, in androgen-treated muscles, the level of multiple innervation drops to only about $70 \%$, suggesting that androgen delays synapse elimination in the LA. Further studies indicated that the effect of androgen treatment during synapse elimination in the LA is permanent, since there is no further loss of multiple innervation for 9 months after exposure to androgen (I uhischer et al, 1992).

These observations were based almost exclusively on anatomical counts of the number of axons that contact individual LA muscle fibers. It is important to determine whether such multiple axons are from different or the same motoneurons since in some instances, apparently separate axons have been found to originate preferentially from the same motoneuron (e.g., $\mathrm{Nu}$ dell and Grinnell, 1983). We addressed this question by using physiological techniques to measure the effect of androgen on the size of LA motor units, since regulation of synapse elimination implies regulation of motor unit size. This was done by measuring the percentage of twitch or tetanus tension of individual motor units relative to the maximal twitch or tetanus tension of the whole muscle.

The selective elimination of multiple inputs may involve some form of competition that is mediated via the muscle fiber (Brown et al., 1976; Thompson and Jansen, 1977; Betz et al., 1980, 1990; Fladby and Jansen, 1987; Lichtman and Balice-Gordon, 1990). Moreover, synaptic effectiveness may be an important factor in determining the competitive strength of synapses (e.g., Grinnell et al., 1979; Wigston, 1980; Bennett and Lavidis, 1984b; Werle and Herrera, 1987, 1988; Herrera and Werle, 1990; Lichtman and Balice-Gordon, 1990). Since androgen may maintain polyneuronal innervation in the LA by preventing or altering synaptic competition, we wished to evaluate the effect of androgen on synaptic strength in the LA. This was done by comparing the estimated size of individual motor units based on their relative tetanus and twitch tensions in normal Ringer's (referred to as the tetanus : twitch ratio), and measuring the safety margin of LA motor nerve terminals in Ringer's with low calcium levcls.

We found that LA motor units decrease in size between P7 and P28 and that androgen prevented some of this decline, consistent with our previous conclusion that androgen influences the pattern of innervation in the LA by regulating synapse elimination. Furthermore, androgen appeared to spare synapses from elimination without increasing their strength. LA synapses in androgen-treated muscles from P10-P28 rats had normal strengths except at P28, where the safety margin of LA synapses in androgen-treated muscles was appreciably lower than normal. Despite this, these lower-strength synapses are apparently stable and will be maintained into adulthood (Jordan et al., 1989b; Lubischer et al., 1992). This androgen-mediated decrease in the strength of LA synapses probably reflects both a decrease in quantal content and an increase in the size of LA muscle fibers.

\section{Materials and Methods}

Animals. Adult Sprague-Dawley female and male rats were obtained from Charles River Laboratories and housed and bred in our own colony. Pregnant females were checked daily for pups. On the day of birth, designated as P1, litters were culled to a maximum of eight pups, sparing males and culling out females. At P7, malcs were castratcd under ether anesthesia and thereafter given daily subcutaneous injections of testosterone propionate (TP; $100 \mu \mathrm{g} / 50 \mathrm{gm}$ body weight) dissolved in sesame oil or comparable volumes of the oil alone until death on P10, P14, P21 or P28 (see Jordan et al., 1989a). Each experimental and control group (TP-treated castrates, oil-treated castrates, and gonadally intact normals) was composed of pups taken from at least two litters for each age.

Dissection, stimulation, and recording procedures for measuring $L A$ motor units. Under ether anesthesia, the LA muscle and the entire nervous pathway to the spinal cord were dissected from rat pups between the ages of P7 and P28. This preparation was placed in a Sylgard-coated dish that was constantly perfused with fresh oxygenated $\left(95 \% \mathrm{O}_{2}, 5 \%\right.$ $\mathrm{CO}_{2}$ ) Ringer's solution (Rees, 1978). In agreement with earlier reports (McKenna and Nadclhaft, 1986; Rand and Brccdlove, 1987), pilot stimulation experiments indicated that between P7 and P28 the LA is innervated by axons traveling only in lumbar (L) ventral roots five and six and never in the adjacent roots (L4 or sacral one). Occasionally, all LA axons were found in either L5 or L6, and on average, each of these ventral roots contained half ( 14.46 vs. 14.54 , respectively) of the total number of LA axons.

In situ, the left and right LA muscles are joined via a midline raphe and encircle the rectum to make bilateral attachments to the base of the penis with each side receiving separate innervation from the spinal cord (Greene, 1935; Hayes, 1965; Cihak et al., 1970). In vitro, the right side was pinned to the bottom of the dish and tension measurements were taken from the left. A fine hook fashioned out of a stainless steel pin was inserted through the tendon end of the left LA and attached via a silk thread to a strain gaugc. A Icngth of fine-gauge Silastic tubing was stretched and pinned across the right LA near the raphe to anchor this half and ensure isometric conditions for measuring tension produced by the left half. The right LA was also crushed near its middle using forceps to ensure that measurements of muscle tension after direct stimulation of the muscle reflected muscle tension produced by only the left $L A$. The left LA was stretched to a length that resulted in maximal nerve-evoked twitch tension, and this length was kept constant throughout the duration of the experiment.

Tension recorded by the strain gauge was amplified and displayed on a Tektronix 5113 storage oscilloscope and an MFE chart recorder. Suction electrodes delivered $100 \mu \mathrm{sec}$ pulses to the nerve, every $2 \mathrm{sec}$ for twitch measurements or at $50-120 \mathrm{~Hz}$ for tetanic stimulation. Platinum plates placed just above and below the muscle delivered $100 \mathrm{msec}$ pulses for direct muscle stimulation; pulses were delivered at $40-50 \mathrm{~Hz}$ for tetanic stimulation. The optimal frequency for maximal direct and indirect tetanus tension was determined separately for each age.

Experimental results were discarded if nerve-evoked or direct muscle tension declined by more than $10 \%$ during the course of the experiment. A total of 47 experiments satisfied the stability criterion. Indirect (nerveevoked) and direct muscle tension was compared to assess the integrity of the preparation. In 41 out of 47 experiments, the muscle tension produced by stimulation of L5 and L6 together equaled that produced directly, indicating that no LA axons had been damaged during the dissection, and allowing an estimate of the total number of LA motor units, as well as measurements of motor unit size and strength. The six remaining experiments, in which direct tension exceeded indirect, yielded information about the size and strength of motor units but not their number, and often involved preparations at $P 28$, when the dissection proved extremely difficult due to the overall increase in muscle mass and calcification of bones.

Procedures for measuring the number, size, and tetanus: twitch ratio of LA motor units. Ventral roots were progressively teased into small nerve filaments using fine forceps until they usually contained one or two LA axons, and no more than four. The number of LA motor units was estimated in teased nerve filaments by counting the number of discrete and reproducible steps in the twitch tension after graded nerve stimulation. The size of motor units was estimated by comparing the amplitude of the twitch (or tetanus) tension produced by the lowestthreshold motor unit in a nerve root or filament with that produced directly by the whole muscle. It was often possible to detect two different "lowest"-threshold motor units in a single filament by changing the polarity of stimulation. Direct twitch tension was assessed several times throughout the course of the experiment, but twitch estimates of motor unit size were based on direct muscle tension measured at the beginning of the experiment. This may have resulted in small underestimates of 
motor unit size based on twitch measurements, since in some experiments, muscle twitch tension declined during the course of the experiment. On average, however, muscle twitch tension at the end of an experiment was at least $96 \%$ of the beginning twitch tension. On the other hand, estimates of motor unit size based on tetanus tension were based on direct tetanus tension measured only at the end of the experiment. This was done as a precautionary measure, since on rare occasions, the muscle tore near the pinned site during tctanic stimulation.

For those filaments containing one or two LA axons, we compared directly the twitch and tetanus tensions produced by individual motor units. Because subthreshold synapses can only exert an influence upon muscle tension via the facilitation and temporal summation of synaptic potentials during the tetanus (Luff and Proske, 1976; Ridge and Thomson, 1980; Fladby, 1987), the tetanus : twitch ratio for individual motor units estimates the proportion of subthreshold inputs in a motor unit and thus provides an indication of the strength of their synapses. At the different ages examined (P7, P10, P14, P21, and P28), we measured twitch amplitude for an average of 67 motor units (from three to six rats, except for oil-treated castrates at P10, where $n=2$ ) per treatment group (normals, TP-treated castrates, and oil-treated castrates). For twothirds of these 67 motor units in each group, we were able to measure both twitch and tetanus tension.

Procedures for measuring the safety margin of $L A$ synapses. In a second set of experiments, calcium concentration $\left[\mathrm{Ca}^{2+}\right]$ in the bathing solution was systematically varied to assess the overall "safety margin" of LA synapses. Different animals were used for these experiments, but the same procedures were used for castrating and treating the animals, and for dissection of the muscle except that the dissection included only the muscle nerve and not the ventral roots. The muscle nerve was drawn up into a suction electrode and stimulated every $3 \mathrm{~min}$ with a train of five pulses ( $100 \mu \mathrm{sec}$ duration) at $1 \mathrm{~Hz}$. Stimulus intensity was maintained at twice the intensity needed to evoke maximal twitch tension. $\left[\mathrm{Ca}^{2+}\right]$ was varied without changes in other cations from $2.0 \mathrm{~mm}$ (normal) to $0.4 \mathrm{~mm}$ in the following sequence: $2.0,1.6,1.2,0.8,0.4,0.6$, $1.0,1.4$, and $2.0 \mathrm{~mm}$. The muscle was considered fully equilibrated at a given $\left[\mathrm{Ca}^{2+}\right]$ when muscle tension no longer changed after at least two consecutive trains of stimulation. This usually occurred within 15-30 min. The safety margin of LA synapses was estimated by comparing the muscle tension produced at a given $\left[\mathrm{Ca}^{2+}\right]$ relative to the muscle tension produced in normal $(2.0 \mathrm{~mm})\left[\mathrm{Ca}^{2+}\right]$. Animals from at least two different litters contributed to each experimental group, with $n=4-6$ animals per group, except for the normal group at P28, where $n=3$.

Statistical analyses. A two-way analysis of variance (ANOVA) design with an isolated control group (P7) was used to determine statistical effects of age and hormone treatment (Woodward et al., 1990). Separate tests were done on the following measurements: (1) number of LA motor units, (2) motor unit size based on twitch tension (all motor units sampled for twitch measurements were included in this analysis), (3) motor unit size based on tetanic tension, and (4) tetanic : twitch ratio of motor units. A two-way ANOVA with $\left[\mathrm{Ca}^{3+}\right]$ as a repeated measure was used to determine whether androgen treatment influenced significantly the safety margin of LA nerve terminals at P28.

\section{Results}

\section{Number of LA motor units}

The number of LA motor units was estimated by counting the number of increments in muscle twitch tension following graded stimulation to teased nerve filaments. In general, the number of LA motor units did not change with age (Table 1). The LA from animals at P7, 10, and 14 had about the same number of motor units (roughly 29) as did the LA from animals at P28, indicating that cell death is probably over by P7 for LA motoneurons. This conclusion is consistent with counts of both healthy and pyknotic cells in the spinal nucleus of the bulbocavernosus (Breedlove, 1984; Nordeen et al., 1985), which contains LA motoneurons (Breedlove and Arnold, 1980; Schroder, 1980; McKenna and Nadelhaft, 1986). However, there was an overall main effect of age on the number of LA motor units ( $p$ $=0.05$ ) caused by a small increase in the number of LA motor units measured at P21 (Table 1). Since this effect is only mar-
Table 1. Mean number \pm SEM of LA motor units $(n=$ number of muscles from different rats contributing to each mean)

\begin{tabular}{llll} 
& \multicolumn{2}{l}{ Treatment } & \\
\cline { 2 - 4 } Age & Normal & TP & Oil \\
\hline P7 & $30 \pm 2.25$ & & \\
& $(n=4)$ & & $28 \pm 0.50$ \\
P10 & $28 \pm 4.36$ & $27 \pm 0.58$ & $\begin{array}{l}(n=2) \\
\end{array}$ \\
P14 & $28 \pm 1.60$ & $28 \pm 0.73$ & $32 \pm 2.99$ \\
& $(n=4)$ & $(n=5)$ & $(n=4)$ \\
P21 & $34 \pm 2.90$ & $33 \pm 1.86$ & $29 \pm 0.75$ \\
& $(n-4)$ & $(n=3)$ & $(n=4)$ \\
P28 & $23 \pm 2.0$ & $29 \pm 0.58$ & $28 \pm 0.00$ \\
& $(n=2)$ & $(n=3)$ & $(n=2)$ \\
\hline
\end{tabular}

The number of LA motor units was not influenced by either treatment or age (except at P21, when there was an apparent small increase in the number of LA motor units)

ginally significant, it probably reflects sampling error that might not be replicated in future experiments. There was no indication that hormone treatment had any effect on the number of LA motor units. Specifically, there was no significant main effect of treatment on the number of LA motor units $(p>0.05)$, nor was there a significant interaction effect between age and treatment on the number of LA motor units $(p>0.05)$.

\section{Estimates of LA motor unit size based on twitch tension}

The size of LA motor units was estimated by comparing the amplitude of twitch tension produced by single motor units to the twitch tension produced by directly stimulating the whole muscle. For example, if a motor unit produced a twitch tension that was $1 / 10$ th the tension of the whole muscle, then the unit was presumed to comprise $10 \%$ of the total number of LA muscle fibers. The accuracy of this measure requires that motor units are composed of muscle fibers of the same mean size. Muscle fiber diameter has been measured directly at ages P14, $P 21$, and P28 in LA muscles from normals and castrates treated with either oil or androgen, and the variability in LA fiber size is relatively small (Jordan et al., 1989a), consistent with the fact that this muscle is uniformly composed of fast-twitch glycolytic fibers (Hanzlikova, 1970). However, the accuracy of motor unit size estimates also requires that the synaptic inputs within a motor unit be above threshold. Data reported below based on tetanus tension indicate that a large proportion of inputs are below threshold near the beginning of synapse elimination in the LA, and therefore suggest that twitch estimates of unit size can in some circumstances be subject to a large degree of error.

Except at P7 and to a limited extent at P10, the amplitude of twitch tension of individual motor units was remarkably stable. Repeated stimulation of individual motor units at $0.5 \mathrm{~Hz}$ resulted in twitch tensions that were virtually identical. However, for many motor units at $\mathrm{P} 7$, twitch tension declined by up to $50 \%$ during the first five to eight pulses, after which the motor unit twitch tension remained relatively stable but showed a 5$10 \%$ random fluctuation in amplitude, in a quantal-like fashion. At P10, this initial decline was only $5-10 \%$ with occasional quantal-like variations in amplitudes. Such fluctuations were not seen when the muscle was stimulated directly. The rapid decline and the inherent variability in the amplitude of the unit twitch tension suggest that synapses at $\mathrm{P} 7$ and 10 are relatively 
Table 2. Mean size \pm SEM of LA motor units based on their twitch (and/or tetanus) tension relative to direct whole muscle twitch (and/or tetanus) tension

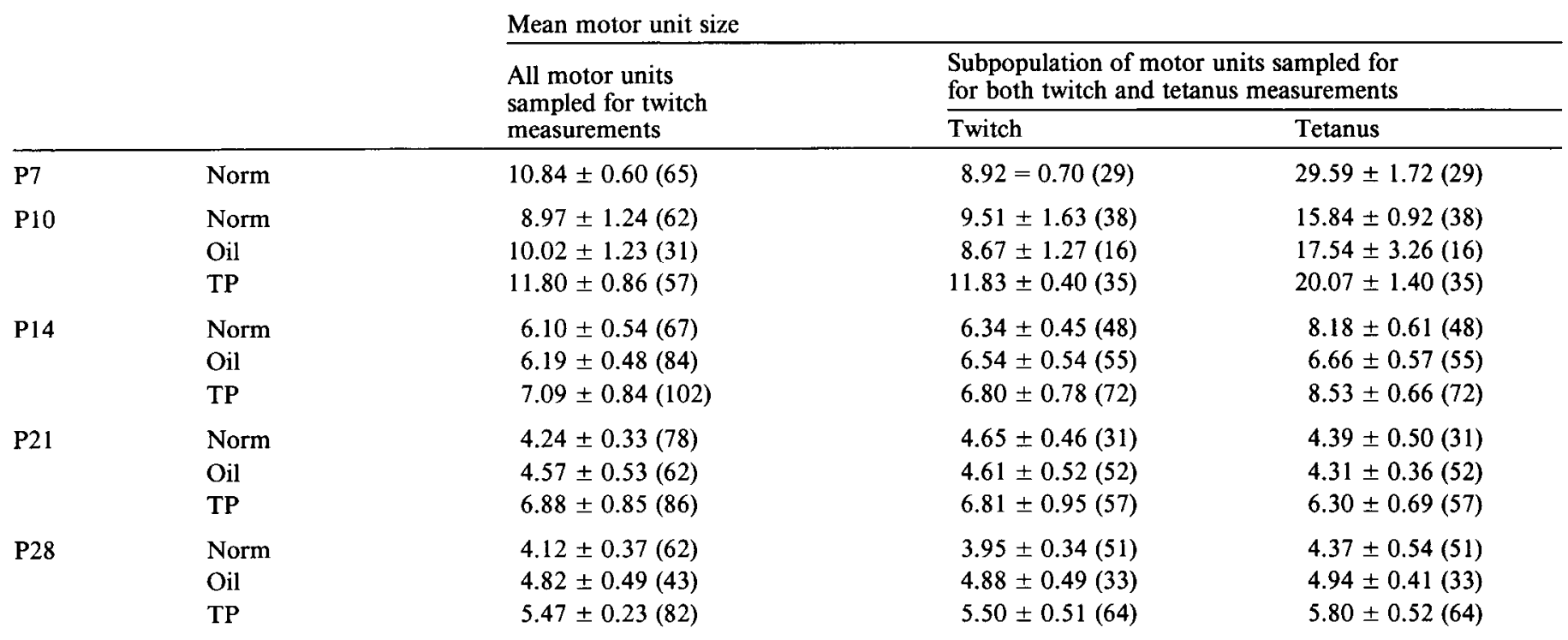

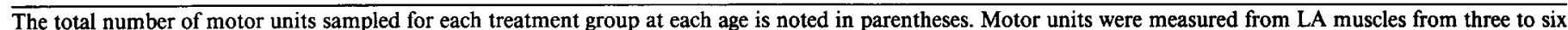

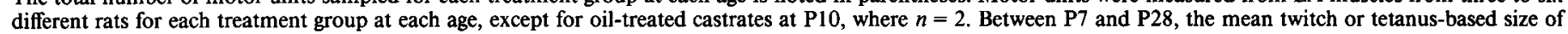
LA motor units decreases dramatically and androgen treatment prevents some of this normal decline in unit size.

weak. Because of this variability, estimates of motor unit size were made by averaging twitch tension over 6-20 stimulus pulses once their amplitudes were relatively stable. Hence, estimates of motor unit size based on relative twitch amplitude at P7 (and somewhat at $\mathrm{P} 10$ ) are probably well below their actual size (Table 2). Motor unit size estimates based on tetanus tension at $\mathrm{P} 7$ and P10 (data reported below) support this contention.

The mean twitch size of all LA motor units sampled was significantly influenced by both age $(p<0.001)$ and treatment $(p<0.01)$, but there was no significant interaction between these two factors ( $p>0.05$; Table 2). Between P7 and P28, there was a substantial decrease in the mean motor unit size, and androgen treatment prevented some of this normal decline (Table 2). Collapsed across ages P10-28, the mean twitch size of LA motor units in androgen-treated muscles was significantly larger than normal ( $p<0.003$ ), while the mean twitch size of LA motor units in oil-treated muscles was not significantly different than normal $(p>0.05)$.

The distribution of motor unit sizes illustrates the decline in motor unit size in all three groups between P7 and P28 (Fig. 1a). At P10, all treatment groups had a similar distribution of motor unit sizes, but by P14, and more so at P21 and P28, androgen-treated muscles had a greater number of large motor units than were present in either normal or oil-treated muscles of the same age. Note that motor units in androgen-treated muscles at P21 and P28 were no larger than that found in normal muscles at P7.

Because the degree of synapse loss may be influenced by the position of the motor axons along the neural axis (Brown and Booth, 1983; Bennett and Lavidis, 1984a,b; Callaway et al., 1989), we compared the mean twitch size of LA motor units located in L5 to the mean twitch size of LA motor units in L6 during the period of synapse elimination. We found no evidence for a differential loss of synapses based on segmental location (L5 vs. L6), nor did we find evidence that androgen acted to spare more LA synapses in one segmental nerve than in the other (Table 3 ).

\section{Motor unit twitch rise time}

Since mature contractile speeds develop during the period of synapse elimination (Close, 1964; Balice-Gordon and Thompson, 1988), we recorded the rise time, which is the time from the beginning to peak amplitude, of some unit twitches. There was a marked and stcady decrease with age in the risc time of twitches (data not shown). The twitch rise times of 110-120 msec found at P7 decreased by P28 to $25-40 \mathrm{msec}$, which is

Table 3. Mean size \pm SEM of LA motor units located in L5 or L6 based on their relative twitch or tetanus tension

\begin{tabular}{lllllll} 
& \multicolumn{2}{l}{ Twitch } & & \multicolumn{2}{l}{ Tetanus } \\
\cline { 3 - 4 } \cline { 5 - 7 } & L5 & L6 & L5 & L6 \\
\hline P7 & Norm & $12.0 \pm 1.60(15)$ & $10.6 \pm 0.91(50)$ & & $25.4 \pm 4.07(9)$ & $31.2 \pm 3.61(20)$ \\
P28 & Norm & $4.2 \pm 0.35(20)$ & $4.2 \pm 0.35(42)$ & & $3.5 \pm 0.46(17)$ & $4.5 \pm 0.37(34)$ \\
& TP & $5.6 \pm 0.41(42)$ & $5.5 \pm 0.35(40)$ & & $5.8 \pm 0.48(33)$ & $6.0 \pm 0.43(31)$
\end{tabular}

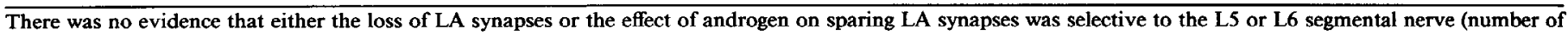
motor units). 
TWITCH
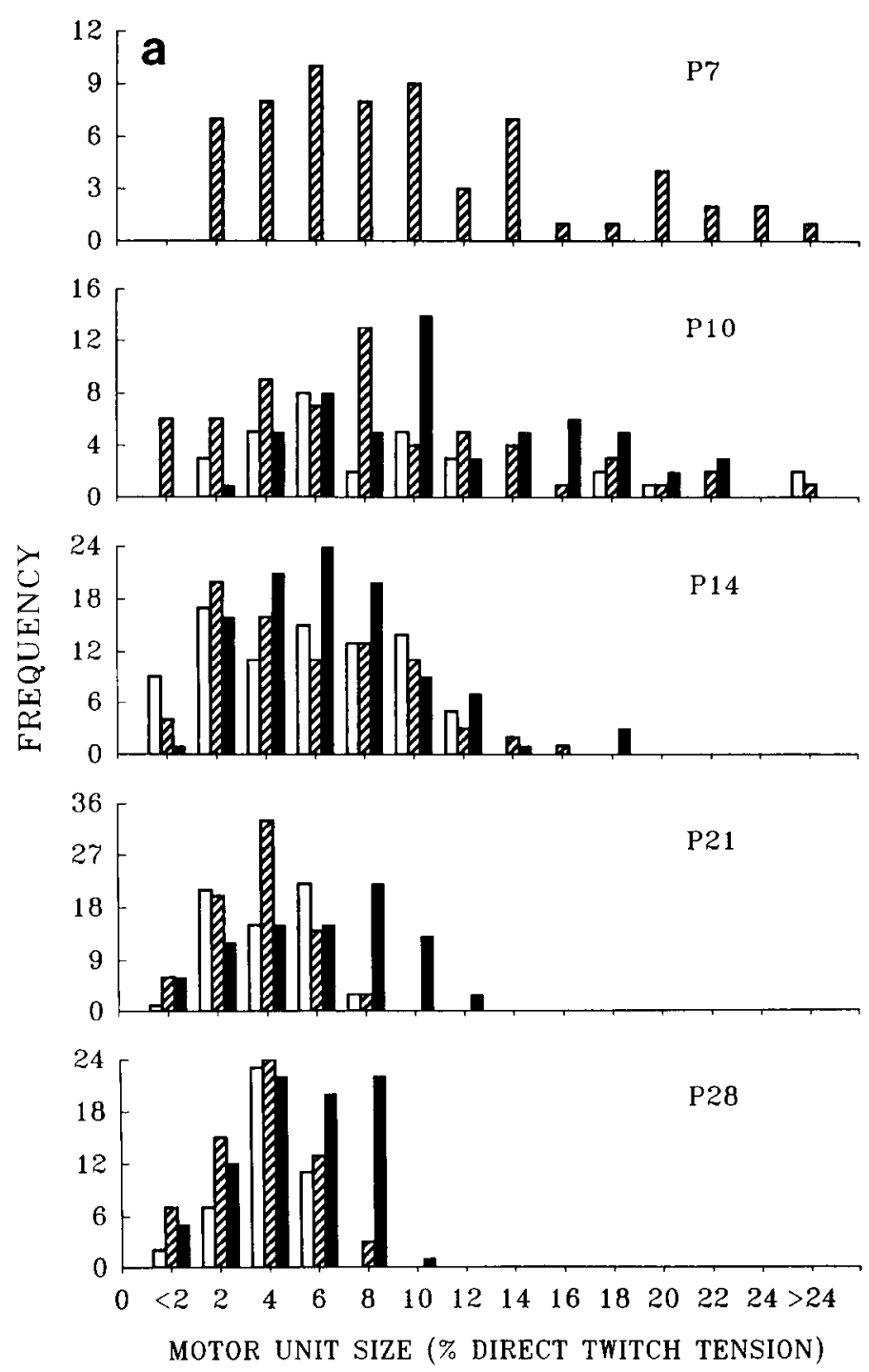

TETANUS
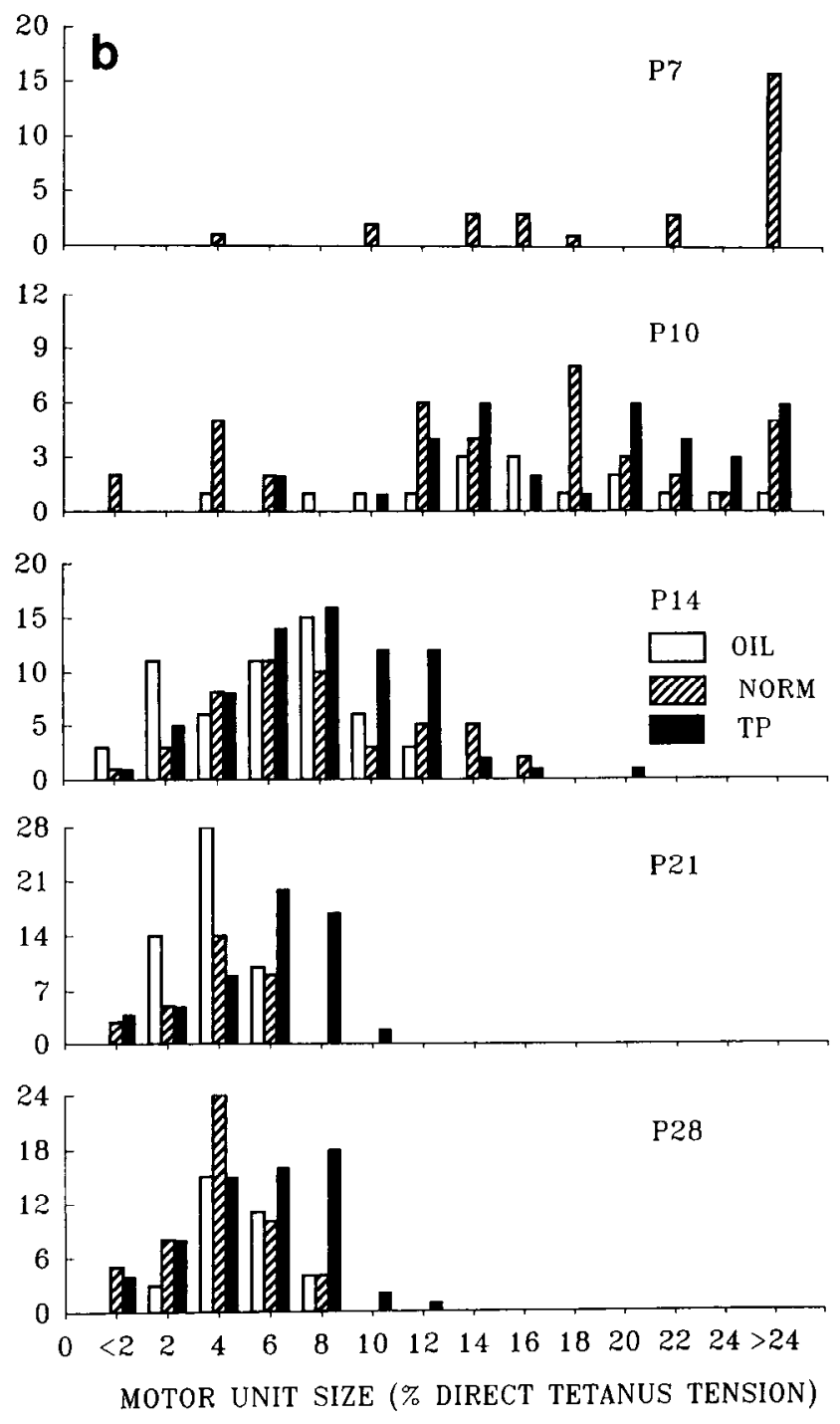

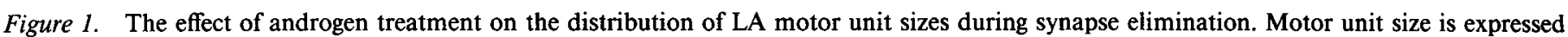

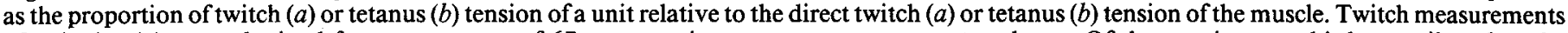

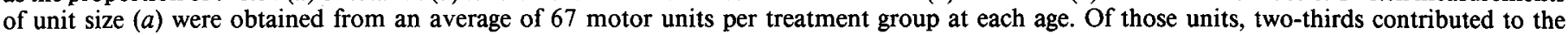

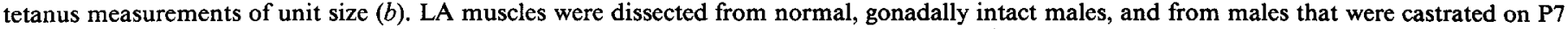

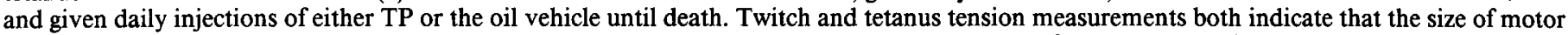

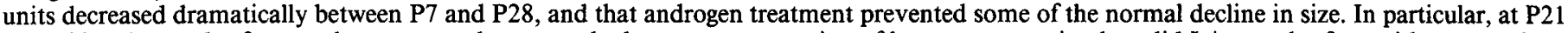

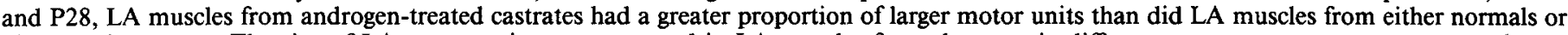

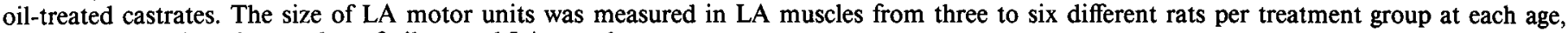
except at P10, when the number of oil-treated LA muscles was two.

similar to those previously reported for adult LA (Souccar et al., 1982). There was no obvious effect of castration or androgen treatment on the rise time of unit twitches at any age, but our failure to detect such effects could be due to the relative inaccuracy of our measure (estimated from the oscilloscope trace). Two reports indicate that castration at $\mathbf{P} 2, \mathbf{P} 20$, or $\mathbf{P} 30$ results in a substantial elongation of the twitch rise time in adult LA muscle, an effect that is at least partially reversed by adult androgen treatment (Vyskocil and Gutmann, 1977; Souccar et al., 1982).

\section{Estimates of motor unit size based on tetanus tension}

Estimates of LA motor unit size based on tetanus tension yielded similar results as for twitch tension measurements. There was a significant overall decline in LA motor unit size with age ( $p$ $<0.001$ ), and hormone treatment influenced significantly the size of motor units $(p<0.01$; Table 2$)$ by preventing some of this decline. There was no significant interaction of these two factors $(p>0.05)$. However, there were some differences between the results based on tetanus tension and those based on twitch tension. At P7 and P14, estimates of motor unit size based on tetanus tension in normal LA muscles were markedly larger than those based on twitch tension (Fig. 2). This was most marked at P7, where tetanus estimates of unit size were three times larger than twitch estimates of motor unit size. Based on tetanus tension, most LA motor units at P7 comprised $>24 \%$ of the total LA (Fig. 1b) whereas few units fell into this cxtrcmc category based on twitch tension (Fig. 1a). In addition, small 


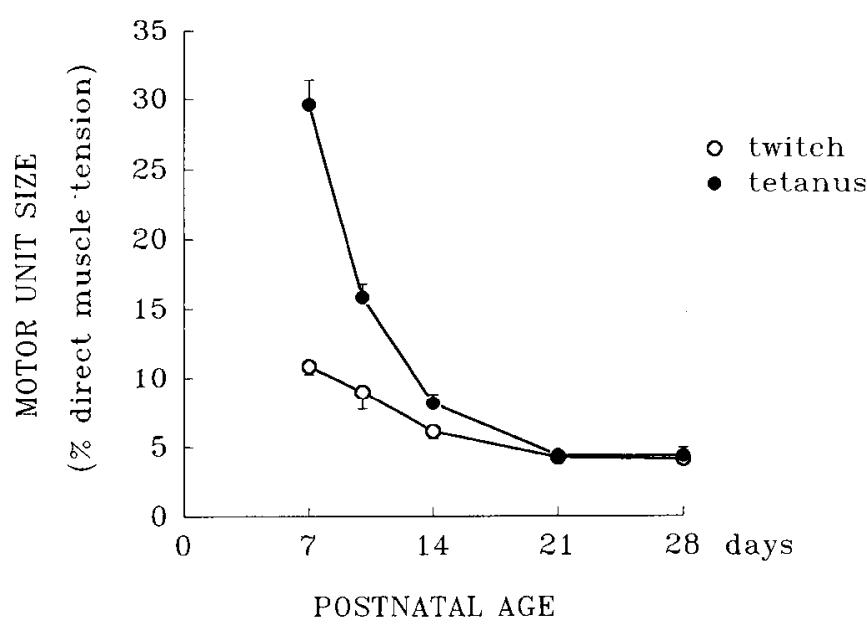

Figure 2. The mean size ( \pm SEM) of motor units in normal LA muscles based on their relative twitch (open circles) or relative tetanus (solid circles) tensions during synapse elimination. As indicated in the caption for Figure 1, tetanus measurements were obtained from a subpopulation of units that contributed to the twitch measurements. Tetanus estimates of motor unit size indicate that LA motor units at P7 and P10 were 3 and 1.5 times larger, respectively, than estimates based twitch tensions, thus suggesting that a large proportion of LA synapses are below threshold at $\mathrm{P} 7$ and $\mathrm{P} 10$, near the beginning of synapse elimination for the LA muscle.

motor units involving $\leq 2 \%$ of the muscle were never observed when size estimates were based on tetanus tension, but were present in twitch estimates of size. Since by P28 some motor units fell into the two smallest categories based on either twitch or tetanus tension, even the smallest LA motor units may lose some of their synapses during synapse elimination.

We cannot attribute this discrepancy to a disproportionate selection of large motor units for tetanic measurements, since their mean twitch size at $\mathrm{P} 7$ and $\mathrm{P} 10$ was virtually the same as that estimated for all motor units sampled (Table 2). Because endplate potentials (EPPs) sum during the tetanizing stimulus, the increased size of motor units based on tetanus tension probably reflects the recruitment of additional fibers that are innervated by subthreshold inputs, some of which were probably suprathreshold at the start of twitch stimulation (Grinnell and Trussell, 1983; Fladby, 1987; Jones and Ridge, 1987). Such subthreshold inputs evidently become much less common as synapse elimination ensues. Tetanus-based estimates of motor unit size suggest that the average size of LA motor units in normal muscles declines by a factor of 6.77 , rather than by a factor of 2.63 suggested by estimates based on twitch tension (Fig. 2). It is interesting to note that between P7 and P10, the tetanic size of LA motor units in normal muscles changed by a factor of almost 2 ( $p<0.001$; Table 2, Fig. 2) whereas estimates of unit size based on twitch tension did not reveal a significant change in LA motor unit size during this period ( $p>0.05$; Table 2, Fig. 2).

\section{Motor unit size and its relationship to the number of anatomically identified inputs per fiber}

Both twitch and tetanus measurements indicate that between P7 and P28, LA motor units get smaller in size and that androgen prevents some of this normal decline in size. Although this result is clcarly consistent with the idea that androgen maintains larger motor units, and thus prevents synapse elimination, it remains
Table 4. The mean number of inputs per LA fiber derived from physiological and anatomical measures

\begin{tabular}{llll} 
& & $\begin{array}{l}\text { Predicted mean } \\
\text { number of inputs/ } \\
\text { fiber }^{z} \\
\text { (physiological) }^{2}\end{array}$ & $\begin{array}{l}\text { Obtained } \\
\text { mean } \\
\text { number of } \\
\text { inputs/fiber } \\
\text { (anatomical) }\end{array}$ \\
\hline P14 & Norm & 2.37 & 2.54 \\
& Oil & 1.93 & 2.03 \\
P21 & TP & 2.47 & 2.48 \\
& Norm & 1.27 & 1.43 \\
& Oil & 1.24 & 1.34 \\
& TP & 1.83 & 2.01 \\
& Norm & 1.27 & 1.30 \\
& Oil & 1.43 & 1.26 \\
& TP & 1.68 & 1.74
\end{tabular}

The mean number of inputs derived from physiological measurements of the number and size of LA motor units confirms previous anatomical counts (Jordan et al., 1989a) of the number of axons innervating each LA fiber. These results indicate that synapse elimination in the LA involves a loss of polyneuronal innervation that androgen partially prevents.

a Calculated by multiplying the mean tetanus-based size of motor units (expressed as the mean percentage of direct tetanus tension) for each group by the overall mean number of motor units (29).

${ }^{b}$ Calculated from direct anatomical counts of the number of inputs per LA fiber (reported as \% multiple innervation in Jordan et al., 1989a).

to be demonstrated that these physiological measures of motor unit size quantitatively account for the level of polyncuronal innervation previously suggested by anatomical counts of the number of axons contacting each LA fiber (Jordan et al., 1989a). To answer this question, we calculated the predicted mean number of inputs per fiber by multiplying the mean size of LA units (expressed as the mean percentage of direct muscle tension) for each group by the grand mean number (29) of LA motor units. For example, if the average size of motor units was $25 \%$ of direct muscle tension and there were four such motor units, then the predicted number of inputs per fiber would be 1.00 (assuming that every muscle fiber is innervated by at least one motoneuron). However, if their mean size was $50 \%$, then the predicted number of inputs per fiber would be 2.0. Estimates of motor unit size based on tetanus rather than twitch tension were used to calculate the predicted number of inputs, since tetanus-based estimates of unit size probably reflect more accurately actual motor unit size (Bagust et al., 1973; Fladby, 1987; Joncs and Ridge, 1987). In addition, the estimated number of motor units used in these calculations was based on the grand mean (calculated across all ages and treatment groups), since neither age (except at P21) nor treatment significantly influenced the number of motor units. The values derived from physiological estimates of the number and size of motor units were compared to the previously obtained mean number of inputs per fiber derived from anatomical observations from LA muscles at P14, P21, and P28 (Jordan et al., 1989a).

There was a striking degree of correspondence between the mean numbers of inputs per fiber calculated from these physiological data and those based on anatomical data (Table 4). For example, at P14, normal LA muscles have an average of 2.54 inputs per fiber based on anatomical counts of the number of axons contacting individual fibers, compared to 2.37 based on physiological measures. Furthermore, anatomical counts show that LA fibers in normal muscles at P28 have 1.30 inputs per 
fiber, whereas androgen-treated muscles have 1.74 inputs per fiber, close to the values (1.27 and 1.68) obtained from physiological data. These calculations provide strong support for the ideas that virtually all of the inputs anatomically identified as multiple inputs originate from different motoneurons, and that the multiple innervation that is maintained by androgen is also polyneuronal.

\section{Tetanus : twitch ratio of $L A$ motor units}

To evaluate synaptic efficacy during synapse elimination in the three groups, we measured the tetanus: twitch ratio for individual motor units, expressed relative to the ratio for the whole muscle (i.e., motor unit size estimate based on tetanus tension relative to the motor unit size estimate based on twitch tension). Thus, a tetanus: twitch ratio of 1 indicates that the apparent size of a motor unit was the same based on its relative tetanus and twitch tensions and suggests that all synapses in that unit were above threshold. Tetanus : twitch ratios above 1 indicate that additional fibers were recruited during the tetanizing stimulus as a result of potentiation and/or summation of subthreshold EPPs (Grinnell and Trussell, 1983; Fladby, 1987; Jones and Ridge, 1987). The extent to which the tetanus : twitch ratio exceeded 1 indicates the proportion of subthreshold inputs in that motor unit.

It should be noted that this measure is subject to several possible errors. For example, this measure may actually underestimate the proportion of subthreshold inputs since not all subthreshold inputs may be brought above threshold by the tetanizing stimulation. While it is difficult to address this issue at the youngest ages (P7 and P10), this appears not to be a factor at the older ages (P14-P28). The fact that the level of polyneuronal innervation based on tetanic stimulation closely matched what was previously predicted based on anatomical counts ( $\mathrm{Ta}$ ble 4) indicates that most, if not all, axons contacting individual fibers are functional and above threshold during the tetanizing stimulus. Alternatively, differences in motor unit size estimates based on twitch versus tetanus tension may overestimate the proportion of subthreshold inputs, since muscle fibers may contract more synchronously during a tetanus than during a twitch. However, such differences in the speed of contraction should occur during contraction of both the individual motor unit and the whole muscle. Hence, the tetanus: twitch ratio probably provides a reasonably good estimate of the proportion of subthreshold inputs.

The relative tetanus : twitch ratio of LA motor units decreased significantly with age (main effect of age, $p<0.001$ ), mostly between P7 and P14, suggesting that subthreshold inputs were present in the LA only at the earliest stages of synapse elimination. At P7, nearly $75 \%$ of LA synapses appeared to be below threshold, since the tetanus: twitch ratio was nearly 4 (Fig. 3). By P14 and older ages, the majority of LA synapses were above threshold (ratio close to 1).

The hormone treatment did not significantly influence the tetanus : twitch ratio of LA motor units ( $p>0.05$; Fig. 3), nor was there a significant interaction between age and hormone treatment on this ratio $(p>0.05)$. However, because androgentreated muscles at P10 had significantly larger motor units than normal based on tetanic measurements $(p<0.02)$, but had a tetanus : twitch ratio the same as normal (i.e., the same proportion of subthreshold inputs as normal), it appears that motor units from such androgen-treated muscles actually contain a greater number of subthreshold synapses than normal muscles

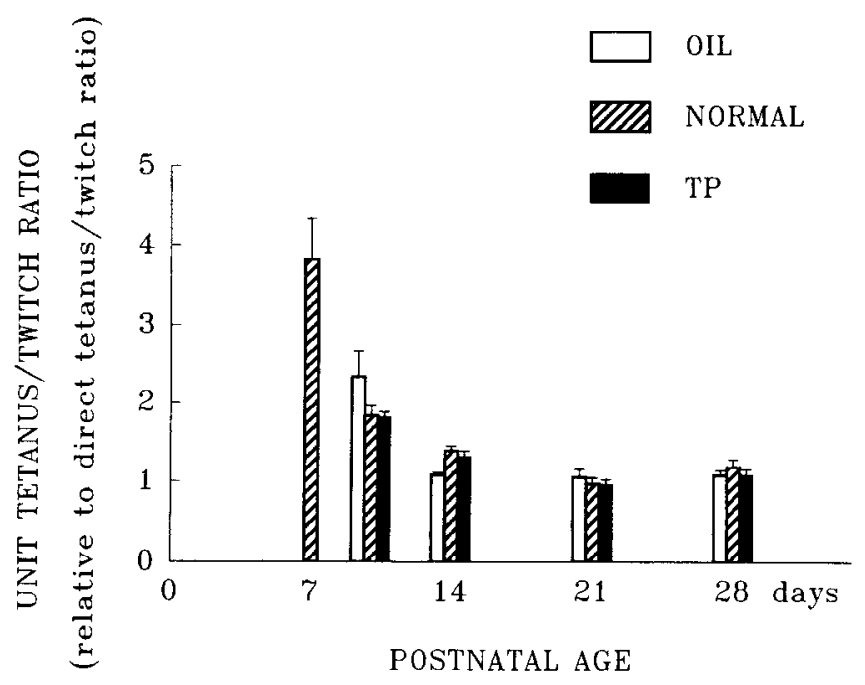

Figure 3. The effect of androgen treatment on the tetanus : twitch ratio of LA motor units during synapse elimination. The mean tetanus: twitch ratio of LA motor units is expressed relative to the mean tetanus : twitch ratio of the muscle (indicated by bar height). Error bars represent the SEM. Treatment groups are as defined in the caption for Figure 1. At P7, the mean tetanus : twitch ratio of LA motor units suggests that nearly $75 \%$ of LA synapses were below threshold. At P14, the tetanus: twitch ratio is approximately 1 , suggesting that most LA synapses were above threshold by this age. Because the decline in the tetanus: twitch ratio between $P 7$ and $P 10$ parallels a similar decline in the size of units based on tetanus but not twitch tension (Table 2), most if not all of the decline in the ratio apparently reflects the loss of subthreshold inputs due to either their selective elimination or strengthening to above threshold.

at this age. This result suggests that androgen can spare synapses from elimination without increasing their strength to above threshold.

\section{Safety margin of LA synapses}

The safety margin of LA nerve terminals was assessed in separate experiments by measuring the effect of $\left[\mathrm{Ca}^{2+}\right]$ on the indirect whole muscle twitch tension. A high safety margin can be inferred if the twitch tension was virtually unaffected when $\left[\mathrm{Ca}^{2+}\right]$ is far below physiological levels. If other factors are equal, a high safety margin implies a high quantal content of EPPs (Grinnell and Herrera, 1980; Grinnell and Trussel1, 1983; Herrera and Grinnell, 1985). However, the measurement of safety margin during the period of synapse elimination is complicated by the fact that the number of inputs per fiber changes. Since our measure of safety margin reflects thc combined release from all inputs to a fiber, changes in safety margin indicate actual changes in synaptic strength and/or changes in the average number of inputs per fiber. The twitch tensions obtained at reduced $\left[\mathrm{Ca}^{2+}\right](1.6-0.4 \mathrm{mM})$ are expressed as a percentage of the twitch tension produced at the normal $\left[\mathrm{Ca}^{2+}\right](2.0 \mathrm{~mm})$.

Developmental regulation of safety margin during synapse elimination. Between $\mathrm{P} 10$ and $\mathrm{P} 28$, there was an overall tendency for the safety margin of LA synapses to increase with age (Fig. 4). At virtually all [ $\left.\mathrm{Ca}^{2+}\right]$ below normal (1.6-0.4 $\mathrm{mm}$ ), we observed a greater decline in twitch tension for LA muscles at P10 than at P28. Such differences, however, were most marked at 0.8 and $0.6 \mathrm{~mm}$. For example, at $\mathrm{P} 10$, the nerve-evoked twitch tension in $0.8 \mathrm{~mm}\left[\mathrm{Ca}^{2+}\right]$ was $62 \%$ of the twitch tension in normal $\left[\mathrm{Ca}^{2+}\right]$, compared to $97 \%$ at $\mathrm{P} 28$, indicating that, on average, LA synapses at $\mathrm{P} 10$ had lower safety margins than LA 


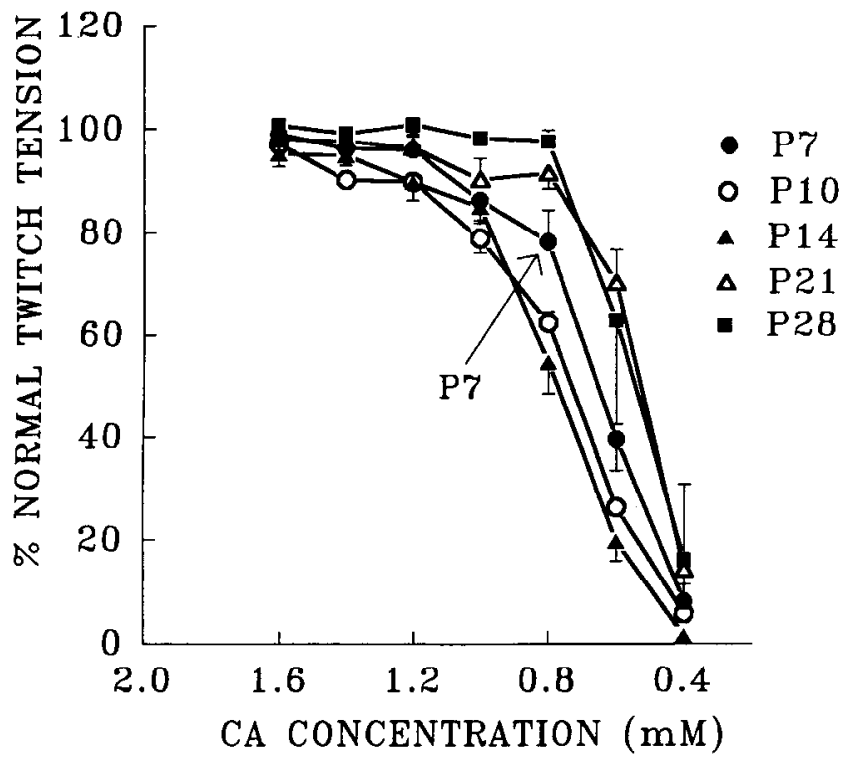

Figure 4. Normal alterations in the safety margin of LA synapses during the period of synapse elimination. The safety margin of LA synapses was measured by recording the relative decline in nerve-evoked twitch tension as $\left[\mathrm{Ca}^{2+}\right]$ was reduced. Measurements were based on LA muscles from four to six different rats per age, except for normals at P28, where $n=3$, and are expressed as the mean \pm SEM percentage of nerve-evoked twitch tension in normal $(2.0 \mathrm{~mm})$ calcium. The safety margin of LA synapses appeared to increase during the period of synapse elimination, but did so in a discontinuous manner: LA synapses at P10 and P14 appear to have similar safety margins, which are lower than the safety margins of LA synapses at P21 and P28. However, LA synapses at P7 appeared to have higher safety margins than LA synapses at P10 and P14.

synapses at P28. The shift occurred primarily between P14 and P21 (Fig. 4). LA nerve terminals at P7 appear to have a higher safety margin than LA nerve terminals at P10/P14 but a lower safety margin than LA nerve terminals at P21/P28, since the $\left[\mathrm{Ca}^{2+}\right]$ curve for $\mathrm{P} 7$ muscles fell between the curves for P10/ P1 4 and P21/P28 (Fig. 4). However, because LA muscles at P7 contain at least twice as many synapses as LA muscles at older ages, the apparent increase in safety margin of LA synapses at P7 probably reflects more rather than stronger synapses.

The effect of androgen on safety margin during synapse elimination. Only at P28 did androgen significantly influence the safety margin of LA nerve terminals (Fig. $5 d$ ). Between P7 and P21, LA synapses in muscles from androgen-treated and oiltreated castrates followed the same overall increase in synaptic strength as in normal muscles (Fig. $5 a-c$ ). At P28, however, there was a significant main effect of treatment $(p<0.001)$ caused by a marked depression in safety margin in androgentreated muscles that was apparent over a wide range of $\left[\mathrm{Ca}^{2+}\right]$ (1.2-0.4 mM). For example, at $0.8 \mathrm{~mm}$, the mean twitch tension in both normal and oil-treated muscles was virtually $100 \%$ of normal $\left[\mathrm{Ca}^{2+}\right]$, while the twitch tension in androgen-treated muscles was about $47 \%$ of normal. Compared to normal and oil-treated muscles, androgen-treated muscles showed significantly lower relative twitch tensions at all values of $\left[\mathrm{Ca}^{2+}\right]$ below $1.4 \mathrm{~mm}$ ( $p$ values $\leq 0.02)$ except at $0.4 \mathrm{~mm}$, where there were no significant differences in twitch tension. Consequently, there was a significant interaction between $\left[\mathrm{Ca}^{2+}\right]$ and treatment at this age $(p<0.001)$. This decrease in safety margin in androgentreated muscles at P28 occurred despite the increased number of inputs per fiber in androgen-treated muscles, suggesting that androgen-treated synapses were appreciably weaker than normal by $\mathrm{P} 28$.

\section{Discussion}

Previous work based on anatomical measures suggested that the neonatal transition from polyneuronal to single innervation of LA muscle fibers occurs primarily between P14 and P28 (Jordan et al., 1988). Moreover, androgen treatment during this time was shown to prevent some of the normal decline in apparent polyneuronal innervation (Jordan et al., 1989a). The present study was aimed at further characterizing synapse elimination in the androgen-sensitive LA by assessing the size of LA motor units during the period when multiaxonal innervation is known to be eliminated from the LA muscle. We predicted that the loss of multiaxonal innervation in the LA would be associated with a decrease in the size of LA motor units. Furthermore, we hypothesized that if androgen maintains multiaxonal innervation by influencing synapse elimination, then androgen should also prevent some of the normal decline in the size of motor units. Both of these predictions were confirmed. A second major goal of this study was to determine whether androgen might alter the course of synapse elimination by regulating synaptic efficacy. We found that androgen appears to spare synapses without selectively increasing their strength.

Regulation of the number and size of LA motor units during the loss of multiaxonal innervation. The loss of multiaxonal innervation in the LA is Iccompanied by changes in the size but not number of motor units. Between $\mathrm{P} 7$ and $\mathrm{P} 28$, the number of LA motor units did not generally change with age nor did androgen treatment alter motor unit number (Table 1). These results indicate that the loss of multiaxonal innervation in the LA and the apparent maintenance of multiaxonal innervation by androgen cannot be accounted for by changes in motoneuron number, consonant with prior conclusions (Jordan et al., 1989a). On the other hand, the size of LA motor units decreased significantly with age and androgen treatment prevented some of this normal decline in motor unit size.

Motor unit size estimates based on tetanus tension indicated that between P7 and P28 there was a sevenfold decrease in the size LA motor units. Motor unit size estimates based on twitch tension revealed a similar but smaller decline in the size of LA motor units (Table 2). The decline in unit size between P14 and P28 probably reflects true changes in motor unit size (i.e., the number of LA fibers each motoneuron innervates) since the estimated level of polyneuronal innervation based on physiological estimates of the number and size of LA motor units is in good agreement with the predicted level of polyneuronal innervation based on previous anatomical counts of the number of axons contacting individual LA muscle fibers (Jordan et al., 1989a). Moreover, the adult number of muscle fibers is present in the LA by P14 (Jordan et al., 1989a), indicating that apparent decreases in motor unit size after P14 cannot be accounted for by increases in the number of muscle fibers. However, if there were increases in the number of muscle fibers between P7 and P14, this could account for the apparent decrease in LA unit size based on muscle tension measurements between these ages. If this were the case, synapses would not be eliminated (i.e., there would be no reduction in the number of muscle fibers each motoneuron innervates), but rather some synapses would move to innervate newly generated fibers. Such a scenario has been described for the fourth lumbrical muscle of the rat (Betz et al., 

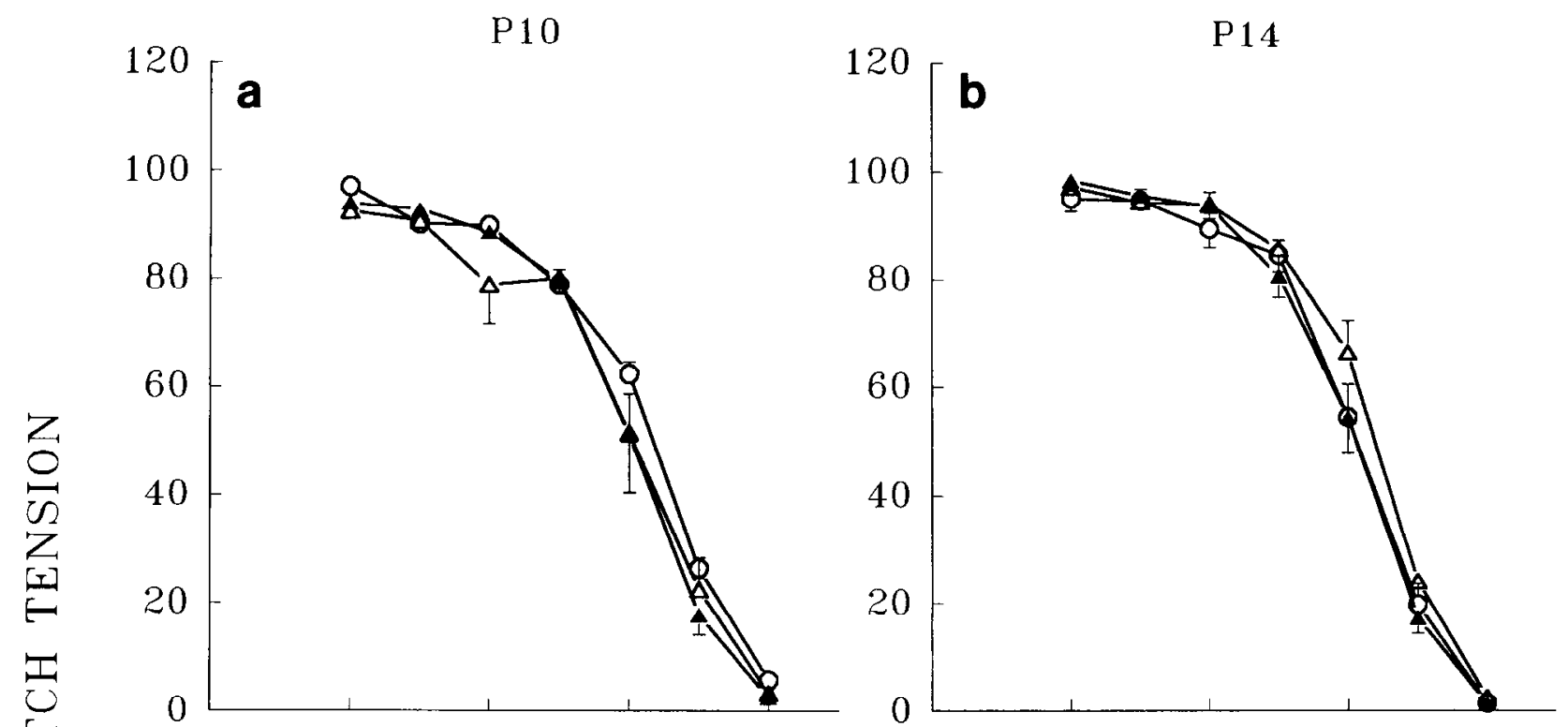

P21
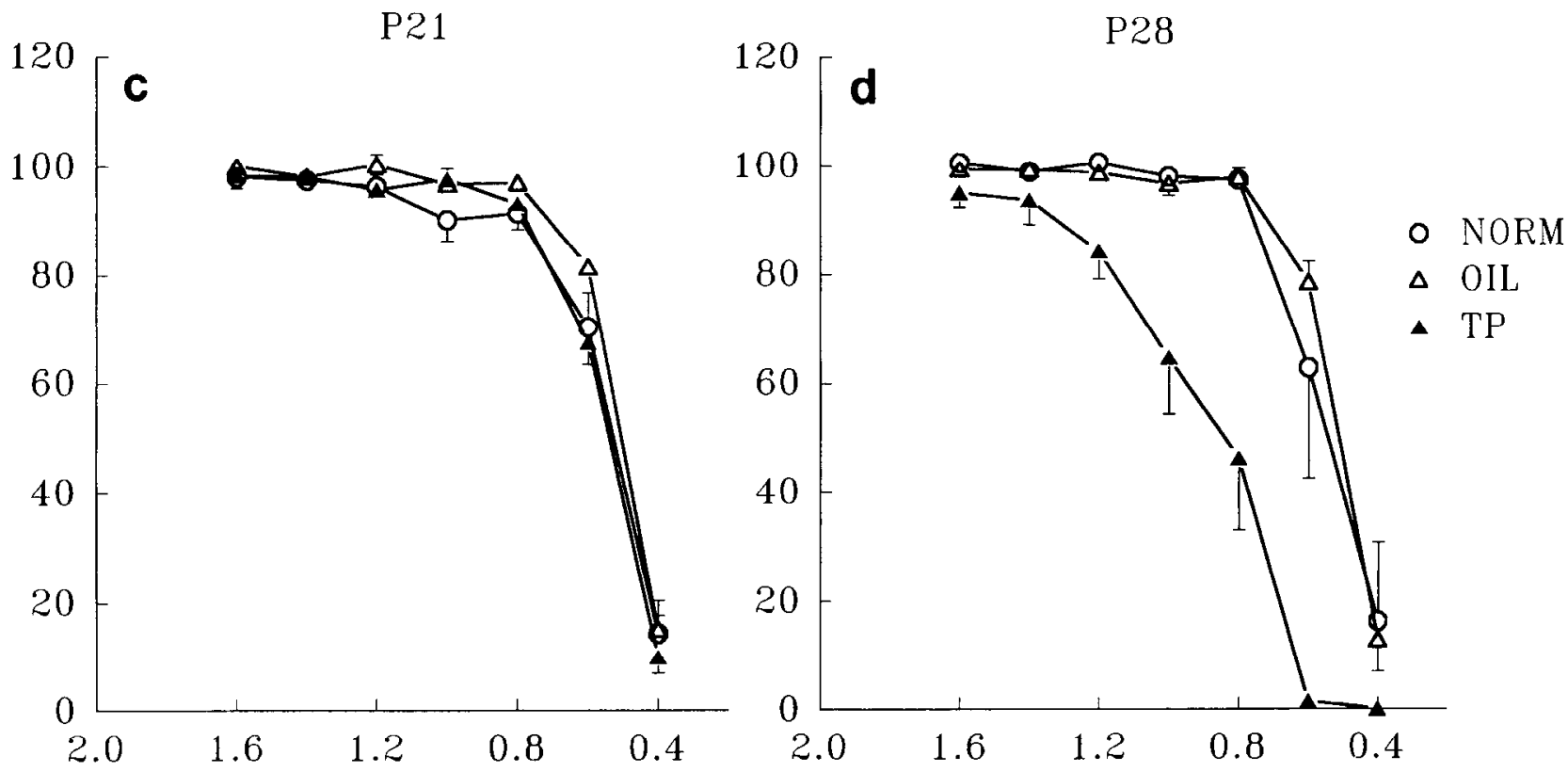

\section{CA CONCENTRATION $(\mathrm{mM})$}

Figure 5. The effect of androgen treatment on the safety margin of LA synapses during the period of synapse elimination ( $a-d)$. Measurements of safety margin are as defined in the caption for Figure 4 (based on LA muscles from four to six rats per treatment group at each age, except $n=$ 3 for normals at P28) and are expressed relative to indirect twitch tension in normal $\left[\mathrm{Ca}^{2+}\right]$ as in Figure 4 . At all ages except P28 (a-c), the calcium curves of oil- and androgen-treated castrates overlapped with those of normals, suggesting that the safety margin of LA synapses was unaffected by alterations in androgen levels at these ages. However, at P28 $(d)$, androgen-treated LA muscles showed a marked decrease in the safety margin of their synapses, suggesting that androgen lowers the strength of synapses by this age. Despite their decreased strength, LA synapses in androgentreated muscles at P28 are stably maintained for at least a year after the end of androgen treatment (Lubischer et al., 1992).

1979). However, between P7 and P10 in normal LA muscles, the twitch-based size of motor units does not change, while tetanus measurements indicate that the size of motor units decreases by about $50 \%$ (Fig. 2). This result suggests that the number of suprathreshold inputs does not change during this period but the number of subthreshold inputs drops by at least half, implying that if muscle fibers are being added during this period, then their increased number must be perfectly offset by an in- crease in the number of suprathreshold inputs that were presumably initially subthreshold. Although this sequence of events is possible, it seems unlikely. Moreover, the effect of androgen on motor unit size at $\mathrm{P} 10$ cannot be easily explained by a general increase in LA fiber number, since androgen's effect would be to maintain or induce the further addition of fibers (Breedlove and Arnold, 1983; Tobin and Joubert, 1991), both of which are inconsistent with androgen increasing the size of motor units. 
Based on current evidence, it seems unlikely that changes in muscle fiber number will account for the observed changes in unit size.

The change in motor unit size can be converted to a change in the number of inputs per fiber by multiplying the number of motor units by their size (\% direct tetanic tension $\times$ number of motor units). The results of this calculation suggested that LA musclc fibcrs at $\mathrm{P} 7$ are each, on average, innervated by eight or nine different motoneurons, whereas by $\mathrm{P} 28$, the majority of muscle fibers receive innervation from only one motoneuron (Table 4). The estimate of eight or nine motor axons per muscle fiber is larger than previous estimates in other systems. For example, Dennis et al. (1981) found that rat intercostal muscle fibers are innervated by as many as six different motoneurons before birth. Our higher estimate may reflect differences between muscles, or in the developmental stage at the time of measurement. The LA muscle is unusual in that the normal time course of synapse elimination in this muscle is significantly delayed (Jordan et al., 1988). Thus, our measurements at P7 might reflect a stage of synapse elimination that normally occurs prenatally in other muscles. However, it is also possible that some of this apparent overlap at $\mathrm{P} 7$ could be due to electrical coupling among developing muscle fibers (Dennis et al., 1981), which would cause our estimates of motor unit size to be spuriously large. Nonetheless, the finding that motor unit size but not number decreases during the period when multiaxonal innervation is eliminated in the LA muscle (Jordan et al., 1988) indicates that synapse elimination in the LA involves an elimination of axon terminals from different motoneurons, as has been described in numerous other rat muscles (Redfern, 1970; Brown et al., 1976; Rosenthal and Taraskevich, 1977; Betz et al., 1979; Dennis et al., 1981; Bennett and Lavidis, 1984b; Balice-Gordon and Thompson, 1988). Because synapse elimination in the LA involves the same cellular changes as synapse elimination in other developing muscles, there may also be common underlying molecular mechanisms.

The effect of androgen treatment on motor unit size similarly suggests that androgen maintains polyneuronal innervation. Present results indicate that androgen treatment prevented some of the normal decline in motor unit size whereas removing endogenous androgen and treating with the vehicle oil had no effect on motor unit size (Table 2). Whereas at P10 and P14 all treatment groups have nearly the same distribution of motor unit sizes, at P21 and P28 androgen-treated muscles contain a higher proportion of large motor units than the muscles from either oil-treated castrates or normals (Fig. 1). For example, at $\mathrm{P} 28,33 \%$ of the motor units in androgen-treated muscles are $\geq 8 \%$ of direct tetanus tension, whereas less than $15 \%$ of the motor units in either oil-treated or normal muscles are of this size (Fig. 1b).

Calculations of the number of neuronal inputs to each muscle fiber based on current physiological data can also be used to test whether androgen's effect on motor unit size quantitatively accounts for the level of polyneuronal innervation previously suggested from direct anatomical measurements (Jordan et al., 1989a). We find a striking degree of correspondence between these two estimates of polyneuronal innervation (Table 4). Both methods of calculating the mean number of inputs per fiber revealed the same relative differences between normal and androgen-treated muscles. For example, at P28, the ratio of androgen-treated over normal muscles for the mean number of inputs based on anatomical counts is 1.34 compared to a ratio of 1.32 derived from physiological measurements of motor unit size and number. These data offer compelling evidence that androgen maintains multiaxonal innervation that is also polyneuronal.

The comparison of anatomical and physiological estimates of polyneuronal innervation (Table 4) also suggests two other conclusions. (1) Previous studies had shown that about half of the multiply innervated fibcrs in the androgen-treated LA at P21 and P28 have separate junctional sites (Jordan et al., 1989a). This androgen-induced development of multijunctional sites on some muscle fibers raised the possibility that androgen might have induced some motor axons to sprout and multiply innervate muscle fibers at separate sites, thus establishing multiple innervation that is mononeuronal and not polyneuronal. The closely matched estimates of polyneuronal innervation based on physiological and anatomical data show that such multijunctional site fibers are innervated by axons from different motoneurons. This result strongly argues that androgen influences the pattern of innervation in the LA through a regulation of synapse elimination and not some other process. Because some LA fibers even as late as P14 are multiply innervated by discrete and separate growth cones (Jordan et al., 1988), it is likely that the multiple junctions on some fibers in androgentreated muscles at P21 and P28 reflect the maintenance by androgen of this earlier growth cone morphology (Jordan et al., 1989a). (2) The good agreement between physiological and anatomical estimates of polyneuronal innervation also shows that the nerve terminals previously counted anatomically are also functional; between P14 and P28, we found no evidence for extremely weak or silent synapses. Similar results have also been obtained in the developing frog cutaneous pectoris muscle (Morrison-Graham, 1983), where the TNBT staining method revealed the same number of axons as estimated based on electrophysiological methods. Hence, the results based on physiological data demonstrate that the TNBT staining method is a reliable and useful approach for studying synapse elimination.

There was, however, some breakdown in the degree of correspondence between the two estimates of polyneuronal innervation. At P21, the values based on physiological estimates were generally lower than those based on anatomical data. Interestingly, this apparent underestimate is corrected when the mean number (32) of motor units for muscles at P21 is used, rather than the grand mean (29). The values are then 1.40 (normal), 1.38 (oil), and 2.02 (TP), which virtually match those obtained from anatomical counts. The apparent increase in motor unit number at P21 may not be due to error and may reflect some sort of rearrangement occurring at this age that is not yet understood. In addition, the correspondence is not as good between physiologically and anatomically derived estimates of the number of inputs per fiber for muscles from oil-treated castrates at $\mathrm{P} 28$. These data reported for oil-treated castrates at P28 were based on experiments done after the completion of all other experiments and may have introduced unforeseen variability in our measures.

It is also clear from the present results that LA motor units decrease significantly in size even in androgen-treated muscles. This could occur because androgen influences only one of several mechanisms that may influence synapse elimination (e.g., muscle fiber-mediated competition vs. motoneuronal capacity for synapse maintenance; Brown et al., 1976; Thompson and Jansen, 1977; Fladby and Jansen, 1987; Herrera and Werle, 1990). 
Alternatively, the timing or dose of androgen treatment may have been inappropriate for a total blockage of synapse elimination. Whatever the reason, it is clear that androgen can be used as a tool to manipulate and hence study the mechanisms of synapse elimination.

Regulation of synaptic strength during synapse elimination. The strength of LA synapses during synapse elimination was cvaluated by comparing directly the estimated size of individual motor units based on their relative tetanus and twitch tensions (referred to as the tetanus: twitch ratio). Synaptic strength was also assessed based on the safety margins of LA synapses, indicated by the relative drop in twitch tension with reduced $\left[\mathrm{Ca}^{2+}\right]$. Both indices suggested that the strength of synapses increased during synapse elimination. Androgen did not appear to alter the strength of synapses as measured in the present study except at P28, where the safety margin of LA synapses in androgen-treated muscles was markedly lower than in either normal or oil-treated muscles at that age.

Tetanus-based estimates of motor unit size exceeded those based on twitch tension at only the earliest stages of synapse elimination (between P7 and P14), a difference that was most pronounced at P7. At this age, tetanus estimates of unit size were three times larger than the estimates based on twitch tension (Fig. 2). This discrepancy is not caused by sampling only large motor units for tetanizing, because the mean twitch size of tetanized motor units was no greater than the mean twitch size of all units sampled (Table 2). Similar differences depending on whether relative tetanus or twitch tension was measured have been observed in the estimated size of neonatal mouse soleus and rat lumbrical motor units (Fladby, 1987; Jones and Ridge, 1987), and were also greatest near the beginning of synapse elimination. Fladby (1987) found that the EPPs greatly facilitated and, to some degree, summed during tetanic stimulation, thus suggesting that the increased size of tetanized motor units is caused by the recruitment of muscle fibers that are inactive during twitch stimulation. In rat lumbrical muscle, Jones and Ridge (1987) found that the twitch size of motor units could be increased to equal their size based on tetanus tension measurements by increasing the $\left[\mathrm{Ca}^{2+}\right]$ in the bathing solution, further indicating that such discrepancies are likely due to the presence of subthreshold junctions. Similar results have also been obtained in adult frog muscles that are normally polyneuronally innervated (Grinnell and Trussell, 1983; Trussell and Grinnell, 1985). Hence, the large discrepancies found in the estimated size of LA motor units based on relative tetanus and twitch tensions probably reflect the recruitment of large numbers of LA muscle fibers that are innervated by subthreshold inputs whose EPPs facilitate and/or sum during the tetanizing stimulus.

Estimates of motor unit size based on tetanus tension indicated that approximately $50 \%$ of the total decline in size occurred between $\mathrm{P} 7$ and P10. In contrast twitch estimates of motor unit size did not change between P7 and P10 $(p>0.05)$, indicating that the number of suprathreshold inputs did not apparently change during this period. One interpretation of these results is that at the beginning of synapse elimination, subthreshold inputs are selectively eliminated while suprathreshold inputs are spared, thus implying that physiologically weak synapses are at a disadvantage compared to those that are stronger. There is considerable evidence supporting this view (e.g., Bennett and Lavidis, 1984b; Werle and Herrera, 1987, 1988; Nabekura and Lichtman, 1989). However, it is also possible that between $\mathrm{P} 7$ and P10, synapses of both strengths are eliminated, but at the same time, subthreshold inputs are strengthened to above threshold to compensate for the elimination of suprathreshold inputs. The effect of androgen on the size but not strength of motor units at P10 helps to decide between these two possibilities. At P10, the mean tetanus: twitch ratio was about 2 for all groups, suggesting that, on average, about half of the synapses in a motor unit were below threshold. However, motor units in androgen-treated muscles at P10 were larger based on both their relative twitch and tetanus tensions (Table 2), indicating that motor units in androgen-treated muscles contained a greater number of both suprathreshold and subthreshold inputs than did motor units in normal muscles at this age. While androgen does not apparently increase the strength of inputs [indicated by the lack of effect on either the tetanus : twitch ratio of motor units (Fig. 3) or the safety margin of LA synapses (Fig. 5a)], androgen does appear to prevent the loss of inputs of both strengths (above and below threshold) at P10, suggesting that perhaps synapses of both strengths are normally eliminated between P7 and P10. This is inconsistent with the notion that subthreshold inputs are selectively eliminated between P7 and P10 in the LA.

If synaptic strength determines which synapses are eliminated, one might expect that synaptic strength would be influenced by a factor that alters the elimination process. Although our results strongly suggest that androgen alters the course of synapse elimination, we did not detect any change in synaptic efficacy that would support the idea that androgen spares synapses from elimination by increasing their strength. Indeed, by P28, synapses in androgen-treated muscles had significantly lower safety margins than normal (Fig. 5). Whether or not synaptic strength is a factor in determining the fate of synapses during synapse elimination, our results suggest that androgen is capable of determining the fate of synapses through a mechanism different than synaptic strength.

As might be expected, the safety margin of LA synapses generally increased during the period of synapse elimination (Figs. $4,5)$. Several factors generally influence the safety margin of neuromuscular synpases, including the size of muscle fibers, the number of synapses per fiber, and EPP quantal content (Grinnell and Herrera, 1980; Grinnell and Trussell, 1983; Herrera and Grinnell, 1985). The diameter of LA muscle fibers increases significantly between P14 and P28 (Jordan et al., 1989a). The resulting decrease in the input impedance of muscle fibers would lower the safety margin unless it was compensated by an increase in the EPP quantal content. In addition, the number of synapses per muscle fiber goes down considerably between P10 and P28 (from about five to about one). Hence, during the period of synapse elimination, the observed increase in safety margin of LA synapses clearly represents a considerable increase in the amount of release from the surviving nerve terminals. However, this apparent increase in synaptic strength may reflect an increase in the strength of only the strongest input at each muscle fiber, so that a weakening of secondary inputs might go undetected.

The developmental change in safety margin appeared to be discontinuous. LA synapses at P10 and P14 had virtually the same safety margin, lower than for LA synapses at P21 and P28 (Fig. 4). Moreover, LA synapses at P7 had an intermediate safety margin, between P10/P14 and P21/P28 (Fig. 4). Our present measurements of safety margin probably do not reflect accurately the changes in release properties of individual LA synaptic inputs during synapse elimination, because synaptic number 
and the size of muscle fibers also change during this period. For example, the number of synapses per LA fiber decreased from about 5 to 2.5 between P10 and P14, making it likely that LA synapses, in general, release more neurotransmitter during this time, even though the safety margin remains constant. Further, even though the number of LA synapses does not change appreciably between P21 and P28, the size of LA fibers does (Jordan et al., 1989a). Their increased size at P28 compared to P21 suggests that the safety margin is maintained by increasing the amount of release per nerve terminal. Finally, LA muscles at P7 contain at least twice as many synapses as LA muscles at older ages, and probably contain fibers that are smaller than at older ages. Thus, the decreased susceptibility to low $\left[\mathrm{Ca}^{2+}\right]$ levels at $\mathrm{P} 7$ as compared to $\mathrm{P} 10 / \mathrm{P} 14$ probably reflects a greater number of synapses per fiber rather than stronger synapses. The high tetanus: twitch ratio and the initial rapid decline in the unit twitch tension at this age also suggest that LA synapses at P7 are, in general, weaker than at older ages. Moreover, only at this age was there a marked quantal-like variation in the unit twitch tension with repeated constant strength stimulation. Similar variability in the unit twitch tension has previously been observed in polyneuronally innervated adult frog muscle (Ridge and Thomson, 1980; Grinnell and Trussell, 1983) and partially innervated neonatal mammalian muscle (Brown et al., 1976). In frog muscles, the fluctuating nature of the twitch amplitude was shown to be associated with relatively weak junctions (Grinnell and Trussell, 1983) and the addition and loss of active fibers in a stimulated motor unit (Ridge and Thomson, 1980). Hence, with repeated low-frequency twitch stimulation of LA motor units at P7, there is probably an initial rapid loss of a large proportion of synapses that fall below threshold, and subsequently, some of the remaining suprathreshold synapses may be just at threshold, and therefore cause muscle fibers to contract only intermittently upon stimulation.

Androgen's only influence on the safety margin of LA synapses was to decrease the margin at P28. At this age, the safety margin of LA synapses in androgen-treated muscles was much lower than in normal or oil-treated muscles. This difference was most marked at $0.8 \mathrm{mM} \mathrm{Ca}^{2+}$; in androgen-treated LA muscles, twitch tension was $48 \%$ of that in normal $\left[\mathrm{Ca}^{2+}\right.$, compared to nearly $100 \%$ for normal and oil-treated LA muscles. However, based on the present data, it is not clear whether the lowered safety margin of LA synapses is caused by an increase in the size of muscle fibers, since androgen also makes fibers larger than normal at this age (Jordan et al., 1989a), or whether the lower safety margin represents a true reduction in presynaptic transmitter release. It is noteworthy that androgen has similar effects on the size of LA muscle fibers at both P14 and P21 (Jordan et al., 1989a) without similar effects on the safety margin of LA synapses at these earlier ages. Moreover, androgen-treated muscles at P28 contain more synapses than either normal or oil-treated muscles. While these observations raise the possibility that androgen may decrease the safety margin of LA synapses at $\mathbf{P} 28$ by reducing their quantal content, direct quantal analysis is required in order to answer this possibility. Despite their lowered safety margin, such androgen-treated synapses are stably maintained, even after the treatment has ended (Jordan et al., 1989b; Lubischer et al., 1992).

We have presented evidence that androgen partially prevents the normal decline in the size of LA motor units during synapse elimination. This result is consistent with the previous observation that androgen prevents the normal loss of multiple in- nervation and provides further evidence that androgen treatment during synapse elimination controls the pattern of innervation in the LA muscle through a regulation of synapse elimination. Furthermore, androgen appears to spare LA synapses from elimination without increasing their strength. To learn more about the mechanisms that underlie synapse elimination, we must determine where androgen acts to regulate this process. Current knowledge indicates that both the LA muscle and its innervating motoneurons contain androgen receptors (Fishman et al., 1990; Jordan et al., 1991), and hence, both are candidate sites for the direct action of androgen on synapse elimination. Moreover, androgen may act indirectly, for example on descending inputs to the LA motoneurons to alter synapse elimination in the LA muscle. Because treatment of neonates with androgen is easy and nontoxic, further studies on the androgenic regulation of neuromuscular synapse elimination may provide novel insights into the mechanisms that determine the synaptic organization of the brain and spinal cord.

\section{References}

Bagust J, Lewis DM, Westerman RA (1973) Polyneuronal innervation of kitten skeletal muscle. J Physiol (Lond) 229:241-255.

Balice-Gordon RJ, Thompson WJ (1988) Synaptic rearrangements and alterations in motor unit properties in neonatal rat extensor digitorum longus muscle. J Physiol (Lond) 398:191-210.

Bennett MR, Lavidis NA (1984a) Segmental motor projections to rat muscles during the loss of polyneuronal innervation. Dev Brain Res 13:1-7.

Bennett MR, Lavidis NA (1984b) Development of the topographical projection of motor neurons to a rat muscle accompanies loss of polyneuronal innervation. J Neurosci 4:2204-2212.

Betz WJ (1987) Motoneuron death and synapse elimination in vertcbrates. In: The vertebrate neuromuscular (Salpeter MM, ed), pp 117-162. New York: Liss.

Betz WJ, Caldwell JH, Ribchester RR (1979) The size of motor units during postnatal development of rat lumbrical muscle. J Physiol (Lond) 297:463-478.

Betz WJ, Caldwell JH, Ribchester RR (1980) The effects of partial denervation at birth on the development of muscle fibres and motor units in the rat lumbrical muscle. J Physiol (Lond) 303:265-279.

Betz WJ, Ribchester RR, Ridge RMAP (1990) Competitive mechanisms underlying synapse elimination in the lumbrical muscle of the rat. J Neurobiol 21:1-17.

Bixby JL (1981) Ultrastructural observations on synapse elimination in neonatal rabbit skeletal muscle. J Neurocytol 10:81-100.

Breedlove SM (1984) Androgen forms sexually dimorphic spinal nucleus by saving motoneurons from programmed death. Soc Neurosci Abstr 10:927.

Breedlove SM, Arnold AP (1980) Hormone accumulation in a sexually dimorphic motor nucleus of the rat spinal cord. Science 210:564 566.

Breedlove SM, Arnold AP (1983) Hormonal control of a developing neuromuscular system. II. Sensitive periods for the androgen induced masculinization of the rat spinal nucleus of the bulbocavernosus. J Neurosci 3:424-432.

Brown MC, Booth CM (1983) Segregation of motor nerves on a segmental basis during synapse elimination in neonatal muscles. Brain Res 273:188-190.

Brown MC, Jansen JKS, Van Essen D (1976) Polyneuronal innervation of skeletal muscle in new-born rats and its elimination during maturation. J Physiol (Lond) 261:387-422.

Callaway EM, Soha JM, Van Essen DC (1989) Differential loss of neuromuscular connections according to activity level and spinal position of neonatal rabbit soleus motor neurons. J Neurosci 9:18061824.

Cihak R, Gutmann E, Hanzlikova V (1970) Involution and hormoneinduced persistence of the muscle sphincter (levator) ani in female rats. J Anat 106:93-110.

Close R (1964) Dynamic properties of fast and slow skeletal muscles of the rat during development. J Physiol (Lond) 173:74-95.

Corpechot C, Baulieu EE, Robel P (1981) Testosterone, dihydrotes- 
tosterone and androstanediols in plasma, testes and prostates of rats during development. Acta Endocrinol 96:127-135.

Dennis MJ, Ziskind-Conhaim L, Harris AJ (1981) Development of neuromuscular junctions in rat embryos. Dev Biol 81:266-279.

Fishman RB, Chism L, Firestone GL, Breedlove SM (1990) Evidence for androgen receptors in sexually dimorphic perineal muscles of neonatal male rats. J Neurobiol 21:694-704.

Fladby $T$ (1987) Postnatal loss of synaptic terminals in the normal mouse soleus muscle. Acta Physiol Scand 129:229-238.

Fladby T, Jansen JKS (1987) Postnatal loss of synaptic terminals in the partially denervated mouse soleus muscle. Acta Physiol Scand 129:73-98.

Greene EC (1935) Anatomy of the rat. Philadelphia: American Philosophical Society.

Grinnell AD, Herrera AA (1980) Physiological regulation of synaptic effectiveness at frog neuromuscular junctions. J Physiol (Lond) 307: 301-317.

Grinnell AD, Trussell LO (1983) Synaptic strength as a function of motor unit size in the normal frog sartorius. J Physiol (Lond) 338: 221-241.

Grinnell AD, Letinsky MS, Rheuben MB (1979) Competițive interaction between foreign nerves innervating frog skeletal muscle. J Physiol (Lond) 289:241-262.

Hanzlikova V (1970) Histochemical fiber types characteristics in the normal and the persistent levator ani muscle of the rat. Histochemie 22:45-50.

Hart BL, Melese-d'Hospital PY (1983) Penile mechanisms and the role of the striated penile muscles in penile reflexes. Physiol Behav 31:807-813.

Hayes KJ (1965) The so-called "levator ani" of the rat. Acta Endocrinol (Copenh) 48:337-347.

Herrera AA, Grinnell AD (1985) Effects of changes in motor unit size on transmitter release at the frog neuromuscular junction. J Neurosci 5:1896-1900.

Herrera AA, Werle MJ (1990) Mechanisms of elimination, remodeling, and competition at frog neuromuscular junctions. J Neurobiol $21 \cdot 73-98$

Jansen JKS, Fladby T (1990) The perinatal reorganization of the innervation of skeletal muscle in mammals. Prog Neurobiol 34:39-90.

Jones SP, Ridge RMAP (1987) Motor units in a skeletal muscle of neonatal rat: mechanical properties and weak neuromuscular transmission. J Physiol (Lond) 386:355-375.

Jordan CL, Letinsky MS, Arnold AP (1988) Synapse elimination occurs late in the hormone-sensitive levator ani muscle of the rat. $\mathrm{J}$ Neurobiol 19:335-356.

Jordan CL, Letinsky MS, Arnold AP (1989a) The role of gonadal hormones in neuromuscular synapse elimination in rats. I. Androgen delays the loss of multiple innervation in the levator ani muscle. J Neurosci 9:229-238.

Jordan CL, Letinsky MS, Arnold AP (1989b) The role of gonadal hormones in neuromuscular synapse elimination in rats. II. Multiple innervation persists in the adult levator ani after juvenile androgen treatment. J Neurosci 9:239-247.

Jordan CL, Letinsky MS, Arnold AP (1990) Critical period for the androgenic block neuromuscular synapse elimination. J Neurobiol 21:760-767.

Jordan CL, Breedlove SM, Arnold AP (1991) Ontogeny of steroid accumulation in spinal lumbar motoneurons of the rat: implications for androgen's site of action during synapse elimination. J Comp Neurol 313:441-448.

Lichtman JW, Balice-Gordon RJ (1990) Understanding synaptic competition in theory and in practice. $J$ Neurobiol 21:99-106.

Lubischer JL, Jordan CL, Arnold AP (1992) Transient and permanent effects of androgen treatment during synapse elimination in the levator ani muscle of the rat. J Neurobiol 23:1-9.

Luff AR, Proske U (1976) Properties of motor units of the frog sartorius muscle. J Physiol (Lond) 258:673-685.

McKenna KE, Nadelhaft I (1986) The organization of the pudendal nerve in the male and female rat. J Comp Neurol 248:532-549.
Morrison-Graham K (1983) An anatomical and electrophysiological study of synapse elimination at the developing frog neuromuscular junction. Dev Biol 99:298-311.

Nabekura J, Lichtman JW (1989) Progressive loss of synaptic efficacy during synapse elimination. Soc Neurosci Abstr 15:165.

Nordeen EJ, Nordeen KW, Sengelaub DR, Arnold AP (1985) Androgens prevent normally occurring cell death in a sexually dimorphic spinal nucleus. Science 229:671-673.

Nudell BM, Grinnell AD (1983) Regulation of synaptic position, size, and strength in anuran skeletal muscle. J Neurosci 3:161-176.

Purves D, Lichtman JW (1980) Elimination of synapses in the developing nervous system. Science 210:153-157.

Rand MN, Breedlove SM (1987) Ontogeny of functional innervation of bulbocavernous muscles in male and female rats. Dev Brain Res 33:150-152.

Redfern PA (1970) Neuromuscular transmission in new-born rats. J Physiol (Lond) 209:701-709.

Rees D (1978) A non-phosphate-buffered physiological saline for in vitro electrophysiological studies on the mammalian neuromuscular junction. Proc Physiol Soc 8P-9P.

Ridge RMAP, Thomson AM (1980) Polyneuronal innervation: mechanical properties of overlapping motor units in a small foot muscle of Xenopus laevis. J Physiol (Lond) 306:29-39.

Riley DA (1981) Ultrastructural evidence for axon retraction during the spontaneous elimination of polyneuronal innervation of the rat soleus muscle. J Neurocytol 10:425-440.

Rosenthal JL, Taraskevitch PS (1977) Reduction of multiaxonal innervation at the neuromuscular junction of the rat during development. J Physiol (Lond) 270:299-310.

Sachs BD (1982) Role of penile muscles in penile reflexes, copulation, and induction of pregnancy in rats. J Reprod Fertil 66:433-443.

Sachs BD, Meisel RL (1988) The physiology of male sexual behavior. In: The physiology of reproduction (Knobil E, Neill J, eds), pp 13931485. New York: Raven.

Schroder HD (1980) Organization of the motoneurons innervating the pelvic muscles of the rat. J Comp Neurol 192:567-587.

Souccar C, Lapa AJ, DoValle IR (1982) Influence of castration on the electrical excitability and contraction properties of the rat levator ani muscle. Exp Neurol 75:576-588.

Thompson W, Jansen JKS (1977) The extent of sprouting of remaining motor units in partly denervated immature and adult rat soleus muscle. Neuroscience 2:523-535.

Thompson WJ (1986) Changes in the innervation of mammalian skeletal muscle fibers during postnatal development. Trends Neurosci 9: $25-28$.

Tobin C, Joubert Y (1991) Testosterone-induced development of the rat levator ani muscle. Dev Biol 146:131-138.

Trussell LO, Grinnell AD (1985) The regulation of synaptic strength within motor units of the frog cutaneous pectoris muscle. J Neurosci $5: 243-254$.

Van Essen DC (1982) Neuromuscular synapse elimination. In: Neuronal development (Spitzer NC, ed), pp 333-376. New York: Plenum.

Vyskocil F, Gutmann E (1977) Anabolic effects of testosterone on the levator ani muscle of the rat. Pfluegers Arch 371:3-8.

Wainman P, Shipounoff GC (1941) The effects of castration and testosterone propionate on the striated perineal musculature in the rat Endocrinology 29:975-978.

Werle MJ, Herrera AA (1987) Synaptic competition and the persistence of polyneuronal innervation at frog neuromuscular junctions. J Neurobiol 18:375-389.

Werle MJ, Herrera AA (1988) Synaptic competition and the elimination of polyneuronal innervation following reinnervation of adult frog sartorius muscles. J Neurobiol 19:465-481.

Wigston DJ (1980) Suppression of sprouted synapses in axolotl muscle by transplanted foreign nerves. J Physiol (Lond) 307:355-366.

Woodward JA, Bonett DG, Brecht M (1990) Introduction to linear models and experimental design. New York: Academic. 